\title{
EXAMEN DE UNA IMAGEN DE CANA DE MAIZ, EL CRISTO DE SANTA TERESA, EN LOS SIGLOS XVII Y XIX
}

\author{
Por Salvador Cruz
}

A Francisco de la Maza

Un pequeño libro de 188 páginas, orgullosamente impreso "en papel mexicano" el año de 1845, nos permite conocer los juicios emitidos acerca de una imagen de caña de maíz, a fines del siglo xvir y en la primera mitad del xIx. ${ }^{1}$ Destinado a historiar el culto de la imagen del Cristo de Santa Teresa la Antigua - sucesivamente nombrado "de Zimapán, del Cardonal, de las minas del Plomo pobre, de las minas de Guerrero", y en el siglo xvir el Cristo de Ixmiquilpa- ${ }^{2}$ es obra esencialmente apologética, si bien lo suficientemente expositiva como para ofrecernos la historia semilegendaria de una imagen que data de los primeros días de la Colonia. El famoso Señor de Santa Teresa, como le llama don Manuel Romero de Terreros, actualmente se encuentra en la Catedral de México. ${ }^{3}$

El libro que nos ocupa tiene cuatro grabados, lamentablemente sin firma. Utilizaremos tres, intimamente relacionados con el Cristo de Ixmiquilpan.

Origen y primera grandeza. Aunque la imagen de caña de maíz resulta a nuestros ojos de indudable factura indígena, al relacionarla con el hombre más acaudalado del siglo xvi novohispano, Alonso de Villaseca, se creyó más conveniente establecer que se había importado "de los reinos de Castilla", puesto que el magnate era toledano. Salvando este punto, la relación se nos aparece puntual:

El muy noble caballero Alonso de Villaseca, si ilustre por su sangre, mucho más ilustre por sus heroicas acciones... entre diversas imágenes sagradas.

1 Historia de la milagrosa renovación de la soberana imagen de Cristo Señor Nues: tro Crucificado, que se venera en la iglesia del Convento de Santa Teresa la Antigua escrita por el Dr. D. Alfonso Alberto de Velasco. México. Reimpresa en papel mexicano, en la calle de la Palma núm. 4. 1845. Lleva cuatro grabados, sin firma.

La edición original reza: Renovación por si misma de la Soberana Imagen de Cristo Señor que llaman de Ytzinmiquilpan (vulgarmente Ysmiquilpa y Esmiquilpa), colocada en la iglesia del convento de San Joseph de Religiosas Carmelitas Descalzas, desta Imperial ciudad de México. Narración histórica que la refiere el Dr. D. Alberto de Velasco. México. Viuda de Francisco Rodriguez Lupercio. Año de 1688. Lleva un grabado de Francisco de Torres.

2 Historia..., pp. 5-6.

3 Romero de Terreros, Manuel. El arte en México durante el Virreinato. México, Editorial Porrúa, 1951. (En el colofón dice 1952.) p. 105. 
que su religiosa piedad trajo a esta Nueva España de los reinos de Castilla, por los años de 1545, fue una la del Santo Crucifijo, que colocó en la iglesia del real y minas que llamaban del Plomo pobre, que eran suyas, y después fueron de Agustín Guerrero, su yerno, y últimamente del licenciado Pedro de Zamora, cura vicario que a la sazón era de ellas, por los años de 1621, distantes de esta ciudad de México a la parte del norte, veintiséis leguas, y cuatro del pueblo de Ixmiquilpa, por cuya razón. apellidaban la santa imagen, ya el Santo Cristo de Zimapán, del Cardonal, de las minas del Plomo pobre, de las minas de Guerrero, aunque más ordinaria y comúnmente el Cristo de Ixmiquilpa, por ser este pueblo la cabecera de aquel partido...

Con ocasión de ser de papelón y engrudó su materia, y por eso muy fácil de destruirse en poco tiempo, cuanto más en el dilatado que corrió desde el año de 1545 hasta el de 1615, que son setenta años que hacía estaba en esta iglesia, se había maltratado tan sumamente, que estaba de arriba a abajo muy negra y desfigurada del todo, de calidad que tenía perdida toda su primera forma... y se Ie habia comido toda la cabeza de polilla, faltándole la boca, narices y ojos; de suerte, que sólo le habia quedado la barba, en cuyo hueco por arriba anidaban los ratones; y con lo muy negro y prieto que estaba todo el cuerpo, no tenía ni se le veía señal alguna de sangre en todo él....4

Dos datos resultan de gran importancia: la consideración de que la imagen era "de papelón y engrudo", y que apareció "por los años de 1545." No está por demás apuntar que era la época del famoso escultor de imágenes de caña de maíz, Luis de la Cerda. ${ }^{5}$

Continúa la historia de la escultura, tan maltrecha "que más provocaba a desprecio que a devoción":

Estando en ese estado, el Illmo. arzobispo de México, D. Juan Pérez de la Serna, de buena memoria, en la primera visita que hizo de su arzobispado el año de 1615, llegó a dichas minas, y reconocida la indecencia de la santa imagen, para quitarla de los ojos y obviar los inconvenientes que ocasionaba su menos veneración y culto, mandó por auto, que dividida en pedazos, se enterrase con el cuerpo de la primera persona grande que muriese. No se cumplió con lo mandado por el auto en más de cinco años que corrieron desde que se proveyó....

Viene enseguida la relación de cớmo "renuévase la Santa Imagen con extraordinarios y admirables sucesos", 7 hasta que el arzobispo manda traerla a México, lo que se efectúa "a la madrugada del día 14 de julio

4 Historia..., p. 6.

5 Romero de Terreros, op. cit., p. 104.

6 Historia..., pp. 6-7.

7 lbid, p. 15. 

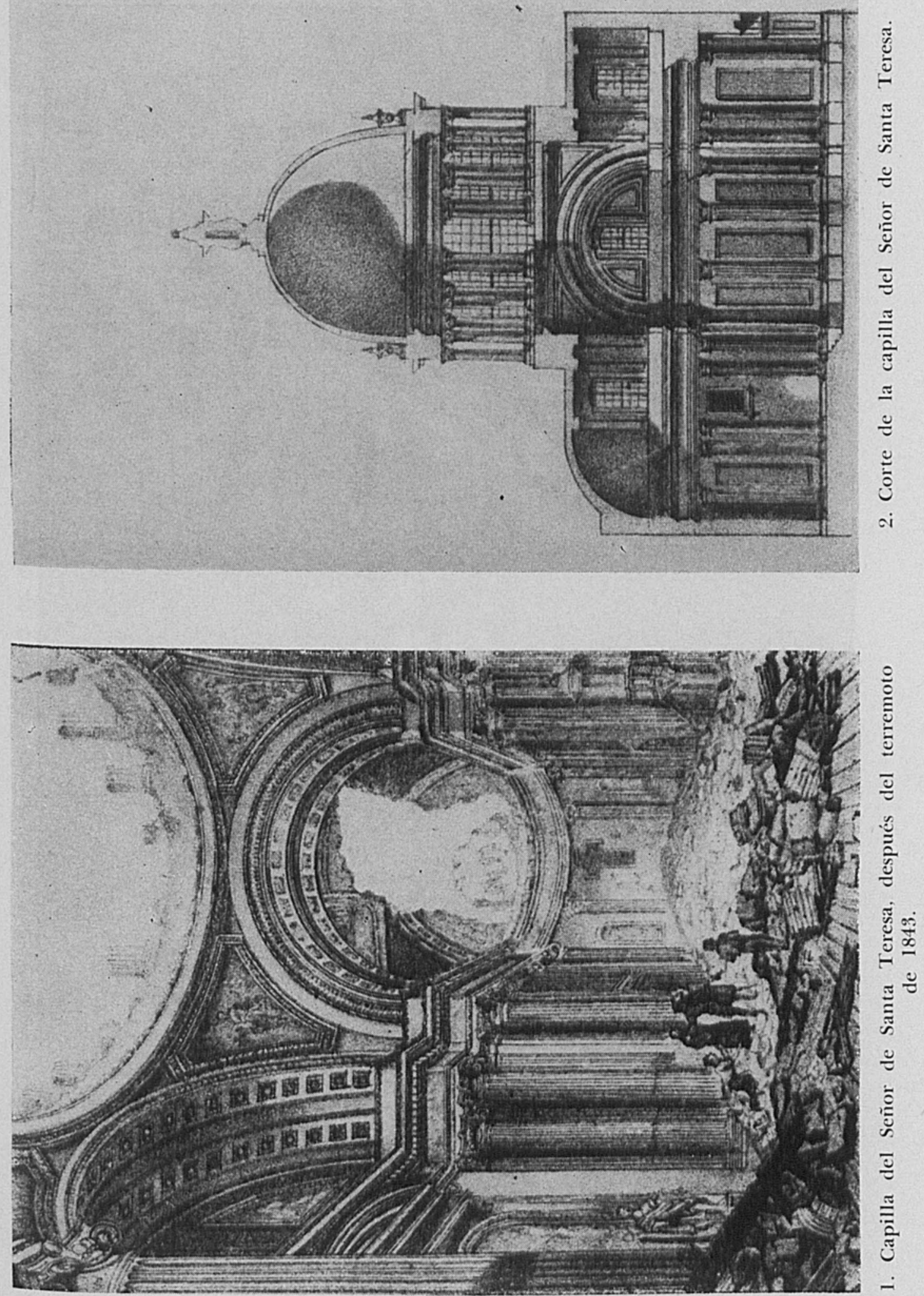
DOI: http://dx.doi.org/10.22201/iie.18703062e.1967.36.843

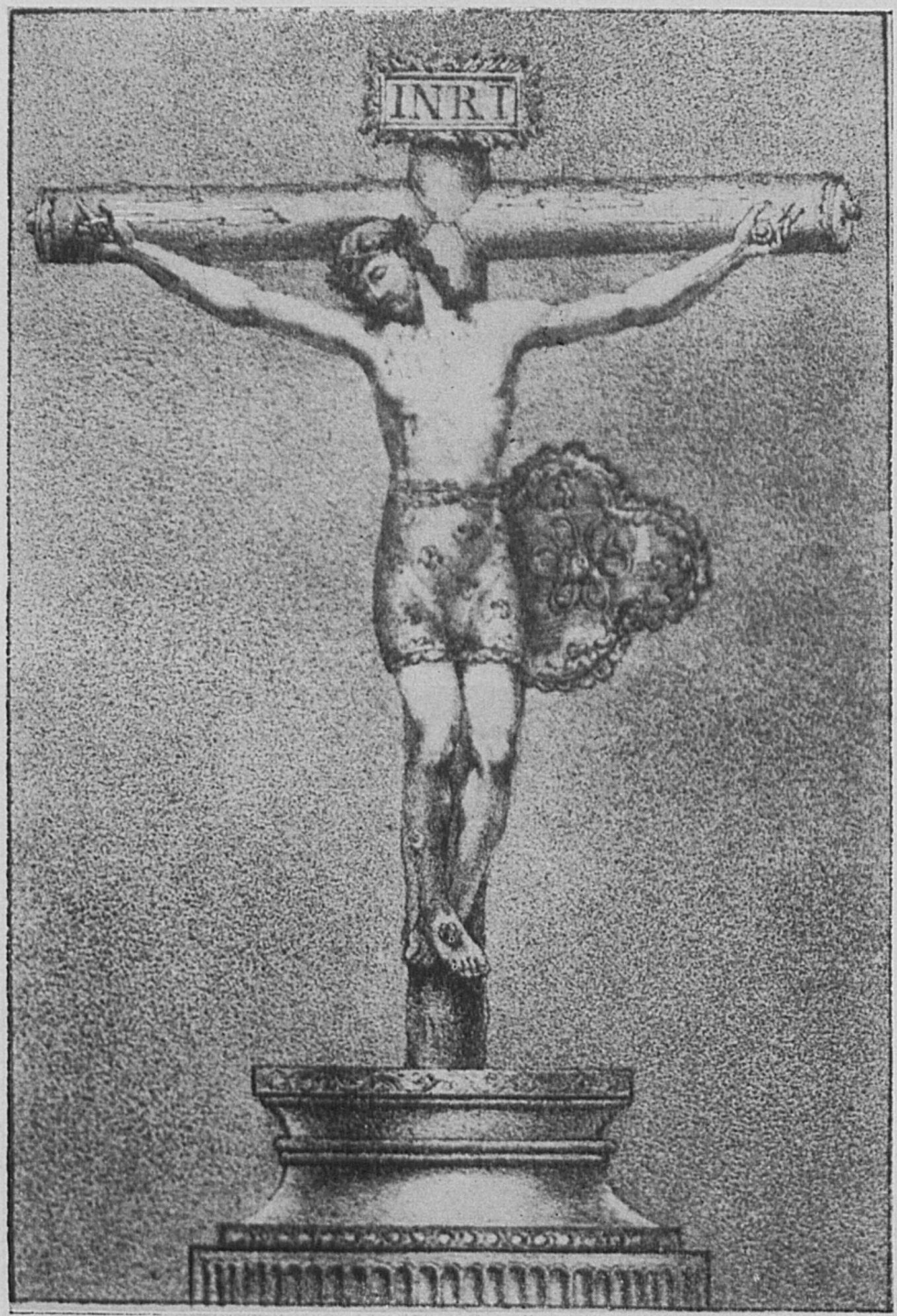

3. El Señor de Santa Teresa. 
del mismo año de 1621." 8 Pero los naturales de Ixmiquilpa guerrean para impedir la salida del Cristo:

... algunas personas, así españoles como indios, procuraron impedir la continuación del viaje y conducción, saliendo tres leguas del Real y una de dicho pueblo de Ixmiquilpa, con armas y clarín para quitarlo, y no habiéndolo conseguido en esta ocasión... salieron segunda vez más de dos mil indios (fuera de los españoles) con arcos y flechas, que con grandes voces, polvareda y alaridos, y sin que el alcalde mayor pudiese defender la santa imagen y estorbar la pendencia, aunque hizo diligencia en orden a ambas cosas, la quitaron y llevaron al convento de San Agustín, de dicho pueblo de Ixmiquilpa, en dicho día 14 de julio. $\theta$

Si hemos querido destacar estos hechos, llamados del cerro del Cardonal, es porque, muchos años adelante, fueron motivo de la decoración realizada por Jimeno y Planes en la capilla de Santa Teresa.

Siguiendo la relación, sabemos que al fin la autoridad episcopal se impuso y al llegar la imagen a la metrópoli, "la tuvo el arzobispo D. Juan de la Serna en su oratorio, y después la pasó al convento de S. José de carmelitas descalzas." 10 Pero como el prelado tuvo serias dificultades con el Virrey Marqués de Gálvez, el asunto culminó con la salida de ambos. Sucedió en la diócesis el Dr. Francisco Manso y Zúñiga, quien le edificó capilla propia al Cristo de Ixmiquilpan, en el mencionado convento carmelita. Quedó la imagen en su nuevo sitio "a 16 de julio de 1634." 11

Un cambio más definitivo emprendió el arzobispo Francisco Aguiar y Seijas, al trasladar al Cristo "a su muy hermosa y suntuosa capilla de la iglesia nueva de nuestra Señora de la Antigua de carmelitas descalzas", lo que aconteció "el día jueves por la mañana, 7 de septiembre de 1684." 12

Todavia alli hubo cambios fortuitos. Primero, al edificar nueva capilla el arquitecto González Velázquez de 1798 a 1813; después, con la ruina por los temblores de 1845 , cuando emprendió la renovación don Lorenzo de la Hidalga.

Examen de la imagen en 1688. El autor de la obra cuya reimpresión seguimos, Dr. Alfonso Alberto de Velasco, fue Cura propio del Sagrario metropolitano y abogado en los autos que del Cristo de Ixmiquilpan

8 Ibid., p. 39.

- Ibid., pp. 39-40.

10 Ibid., p. 49.

11 Ibid., p. 55.

12 Ibid., p. 57. 
mandó formar entre 1688 y 1689 el arzobispo Aguiar y Seijas. Confiesa haber tenido en sus manos la imagen, por lo que no vaciló en declarar: "su muy hermosa proporción, que según inspección que de ella hicieron juridicamente los maestros de escultura, ensambladura y pintura... es en la manera siguiente":

La materia de que está formada esta santa imagen se reconoció con evidencia, que por lo interior (que es lo que llaman alma los del arte) es de madera muy cosa semejante al corcho, y a los que los de la tierra llaman zumpantle, y la superficie que forma y perfecciona todas las partes del cuerpo, es de papel de estraza y engrudo; los extremos, cabeza, manos y pies son de la misma madera, lo uno y lo otro tan sujeto a corrupción y a carcomerse de polilla como es notorio, pues dicha madera parecida al corcho, es de suyo muy porosa, frágil y muy fácil de deshacerse con los dedos, y el papelón y engrudo es materia muy sujeta a la polilla y gusano, como se ve por la experiencia en los libros aforrados de cartón.

La estatura de su cuerpo es del natural, como algo más de dos varas, y todo tan suave como su ley y su peso tan leve como sus preceptos.

Es su anatomía tan hermosa y bien proporcionada, como el cuerpo tan bien cortado de tercios, que en ninguna manera admite censura alguna, sino mucha admiración; porque los brazos y piernas (que suelen ser en otros crucifijos las partes más expuestas a los yerros de los artifices), son de tan igual correspondencia, como todas las demás partes donde los músculos, nervios y coyunturas hacen un todo perfectísimo, a quien la simetría, proporción y dibujo, hacen un rostro hermosísimo, no afeminado sino como de varón perfecto y soberano rey.

La inclinación de la cabeza hacia el lado derecho, es moderada, de manera que de cualquier parte se ve muy bien y enteramente su rostro.

El cabello que tiene propio, ondeado, y en lo largo con ajustada proporción, es avellanado o castaño oscuro y agraciado.

Los ojos, a lo que se ve por entre los párpados, tiene como arrasados o quebrados muy al natural, como de difunto, que causan temor y respeto; la nariz hermosa y proporcionada, la barba hendida por enmedio y prolongada como cuatro dedos, toda llana, espesa y muy hermosa, como también el bigote copado y unido a la misma barba, y con su disminución en los extremos, la boca algo abierta, los labios denegridos.

El pecho tiene levantado por el lado del corazón más que por el lado derecho propiamente, como de agonizante y difunto, y una bendidura entre la segunda y tercera costilla del lado izquierdo, que al tacto se hunde algo, y se muestra blando y benigno. 
El cendal se ve claro y distintamente tener algunas medallas de oro que son del tiempo antiguo, y no se usan ahora, las cuales denotan la mucha antigüedad de esta santa imagen.

Su colorido es muy hermoso; no es de pulimento ni de mate o medio mate, ni pudieron los maestros del arte conocer ni distinguir qué género de encarnación sea; pero es tan agraciado y tan sobre lo artificial, que no puede ser mejor; y tan reciente, y rozagante, que parece acabado de hacer, siendo así que las imágenes muy antiguas se ponen negras o muy amarillas.

En lo que toca a la sangre, tiene en la frente a raíz del cabello una cinta de sangre, que muestra haberla cogido fresca, y limpiándola llevando el lienzo con violencia hacia el lado derecho, y de dicha cinta penden algunas gotas de sangre, unas que caen derechas por encima de la cinta, y otras por debajo de ella que demuestra haber caído después de limpiada la cinta de referencia.

Entre las gotas de sangre que tiene el rostro, se ve una que sale de la boca y cae hacia el labio por el lado derecho, adonde está inclinada la cabeza que es muy a lo natural, y otra gota pequeña que tiene sobre la nariz al lado izquierdo.

La sangre que sale de la llaga del costado, va corriendo hasta el cendal, y de allí entra por debajo de él, hasta salir por el muslo derecho, y va goteando por la espinilla de la misma pierna derecha, y demuestra ser limpiada.

La sangre que sale de las llagas de las manos, está chorreada a lo natural.

En las espaldas tiene una pequeña llaga, de donde sale alguna sangre harto hermosa, como también de las rodillas.

En la llaga del pie derecho, que cruza sobre el izquierdo, se ven muchas gotas de sangre, y de la misma chorrean sobre el pie izquierdo tres gotas, y por la planta del pie desde la llaga para los dedos de los pies se ven muchísimas gotas de sangre tan menudas, como rociadas, que no pueden ser de pincel.

Y demás de esto, tiene por varias partes del cuerpo algunas señales de sangre, que demuestran haberse limpiado, y debajo de la barba algunas denotan estar cuajadas, y parte de ellas pareció a los maestros del arte ser artificial, que debió de ponérsela el que la encarnó en su principio y parte de ellas, y la mayor ser muy natural...

La cruz en que hoy está la santa imagen, es de cedro, en forma de un tronco de árbol grueso, y muy hermoso, y con los tres clavos de hierro plateadas las cabezas, se lo puso todo, el año de 34, cuando la colocó el Dr. Francisco Manso en su capilla de la iglesia vieja...13 
El examen que Velasco nos transmite y que dice estar apoyado en el dicho de pintores, carpinteros y escultores, resulta un curioso antecedente de la "Maravilla Americana", obra de conjunto promovida en torno a la Guadalupana por Miguel Cabrera (1756).

Examen de la imagen en 1875. Destruida la capilla anexa de Santa Teresa la Antigua en el temblor del 7 de abril de 1845, el arzobispo Dr. Manuel Garduño y Posada procedió al reconocimiento de los daños. Entre otros acompañantes en tan ingrato recorrido estuvieron el "profesor de medicina y catedrático del instituto médico, D. Manuel Andrade, y el director del ramo de escultura de la academia nacional de San Carlos, D. Francisco Terrazas." 14

A la imagen se le encontró decapitada, con los brazos desprendidos, aplastada: "cubierta de polvo, llena de multitud de piedras pequeñas, ciesconcertada completamente la configuración del cuerpo; por último, del todo separadas muchas piezas, cuyo lugar no podía señalarse fácilmente." ${ }^{15}$ En tal estado, la primera impresión de la persona más entendida en la materia, nos es transmitida por el anónimo cronista:

La materia de que está formado el cuerpo del Señor, parece diversa, según el examen del escultor referido D. Francisco Terrazas, quien opina que todo el tronco con las piernas y brazos está hecho de cañas de panizo, que también llaman caña de Indias en España; y los pies y manos de zumpantle, cubierto todo de papel fino, sobre alguna preparación de yeso u otra pasta, de la cual parecen construidas las orejas, nariz y pelo de la santa cabeza. Esta, hueca como lo está todo el cuerpo excepto las extremidades, ha parecido más difícil de calificar su materia al perito, inclinándose, sin sostenerlo, a que es una especie de cartón, fortalecido interiormente, lo mismo que todas las partes huecas, de una cosa como gamuza, ante u otra piel muy delgada. Finalmente, en el centro de la sagrada cabeza se encontró un bracito de madera, de una cuarta de largo, en forma de muletilla por un extremo y roto por el otro, el cual servía sin duda para adaptar al cuerpo la sagrada cabeza. ${ }^{16}$

Con especial empeño, Terrazas tomó a su cargo la restauración de la imagen y sustancialmente a él se debe adjudicar la insistencia en declarar

13 Ibid., pp. 61-65.

14 Ibid., p. 159.

15 lbid., p. 171.

16 lbid., pp. 164-165. 
que el Cristo de Santa Teresa era obra de factura sui generis, "muy distinta de lo que hasta aquí se habia creido generalmente."

Pero en este punto es preferible dejar correr la pluma del anónimo cronista y editor del medio siglo xix, que completa su extraordinaria relación con un dictamen, nada menos que del benemérito sabio mexicano Leopoldo Río de la Loza -es decir, la ciencia al servicio del arte en México. Leemos:

La construcción, pues, de esta imagen, es de un sistema enteramente desconocido en el dia, según han confesado varios artistas inteligentes que la han visto, sin que quede la menor duda en que la materia de que se compone es muy distinta de lo que hasta aquí se habia crefdo generalmente. Toda ella esta formada sobre una horma hueca, que parece construida en molde desde el cuello y una pequeña parte de los hombros, hasta la mitad de las piernas, y cuya horma está hecha en dos mitades, una que forma todo el frente o parte delantera, y la otra, la posterior, adheridas o ensambladas ambas por medio de unas lienzas de la misma materia que dicha horma, y de que se hablará más adelante. La cabeza está igualmente hueca y formada de dos mitades de arriba a abajo, como se indicó en la acta. Los brazos también están huecos, mas no se distingue en ellos la clase de horma sobre que está formado el cuerpo, sino unos simples rollos cilíndricos de capas de la materia que se describirá. Las manos, desde la muñeca, son macizas, de zumpantle, así como los pies desde los tobillos, y desde estos puntos para arriba, de una manera que parece haya, la cual entra un poco en la horma que forma lo demás del tronco.

De esta manera está construido el interior de la imagen, en el cual no se ha encontrado más pegamento conocido que la cola común, de la misma naturaleza que la que hoy se usa, según el examen que de ella se ha hecho; mas esto en tan corta cantidad y tan pocos puntos, que ha sido necesaria: bastante atención para descubrirla; encontrándose en mayor cantidad todavía que la materia mencionada, la de búcaro o arcilla blanca de que está como embarrada toda la horma por la parte interior, y espolvoreada entre los pliegues de los rollos de los brazos y piernas.

Sobre dicha horma y rollos está formada la parte muscular del cuerpo, con cañas de maíz del pais, o de otras enteramente iguales, unidas entre sf con una pasta formada también de las mismas cañas pulverizadas, la cual cubre todos los huecos que hay entre unas y otras. De esa misma pasta están talladas algunas partes de la cabeza, como el pelo, orejas, barba, etcétera, encontrándose siempre la caña en las partes muy abultadas.

Construidos así todos los músculos, cabeza, manos y pies, está formado el cutis de una ligera capa de las mismas que hacen la horma, pero tan fina y delgada, que a pesar del colorido no es más gruesa que el papel común. El modo con que haya sido aplicado ese colorido tampoco es fácil de explicar, pues con dificultad se salta ni descascara, separándose casi siempre adherido a alguna parte de las ligeras capas del cutis; una prueba de esto es haberse conservado en la multitud de fragmentos en que fue destrozado 
el propio cutis de la imagen, que con gran parte de las cañas se desprendió enteramente de la horma y aun de la parte sólida del cuerpo. Lo más notable en este punto es la sangre, cuya viveza y frescura es tal que parece, no acabada de pintar, sino que escurre realmente en unas partes, que está coagulada en otras, y como impregnada y cuajada entre los poros, formando manchas en otras partes de una manera tan natural, que no es posible explicar y que los artífices han confesado francamente que no será dable igualar.

Volviendo ahora a la materia que compone la horma interior y todo el cutis del Señor, parece que nada dará mejor idea, que la lectura del examen que de ellas se hizo por el señor profesor de farmacia don Leopoldo Río de la Loza, bien conocido por su capacidad natural, profunda instrucción y asidua aplicación a su ramo, quien por disposición del Illmo. señor arzobispo reconoció dicha materia extendiendo su parecer en la forma siguiente:

"El Señor de Santa Teresa está formado de pequeños pedazos de caña de maíz, unidos entre sí y a la armadura por medio de cola común de la que se usa hoy. Los espacios que dejan las cañas, están llenos de una pasta hecha con aserrín de la misma caña y cola. Los pies y las manos son de madera; la cubierta o armadura es de hojas de una especie de papel, preparado por un método sencillo, unidas, y tienen el grueso, aspereza y textura del coco blanco que sirve para fardos, etcétera. Habia, según se me ha informado, en la parte anterior del hombro derecho una sustancia dura y fibrosa, formando cuerpo con una de las hojas del mismo papel; examinada dicha sustancia, hallé ser un pedacito de penca de maguey bien caracterizada. No hay duda que dicho papel, aun cuando no sea sacado de la palma, es producto vegetal, obtenido por sólo la separación de la parte fibrosa de hojas o corteza de alguna planta. El Señor deja percibir un aroma análogo al de los bálsamos, pero poco activo. México, mayo 21 de 1845. L. Rio de la Loza."

Réstanos instruir de otros particulares descubiertos en el progreso de la composición que se está haciendo.

Desde luego se encontró que a pesar de haberse destrozado todo el cutis de la santa imagen, se preservó lo más de la horma, y completamente los rollos sobre que están construidos los brazos, no sufriendo la primera otro accidente que haberse despegado las dos mitades por la parte del lado derecho desde la axila hasta el punto del hueso ilíaco, y una ligera rotura en el lugar de la región correspondiente a los cartílagos de las costillas del lado derecho, cuyos puntos se cosieron fácilmente con fuertes torzales de seda, y bastante humedecida toda la horma con agua caliente, recobró desde luego su primitiva forma por medio de unas almas o trozos de zumpantle, que se le quitaron después por haber adquirido tanta consistencia cuanta podía tener anteriormente, pues es tan gruesa como una piel de res, aunque extremadamente leve.

Al sacudir la imagen del polvo de que estaba encubierta, se encontró entre el hueso ilíaco del lado izquierdo y la última costilla falsa, un 
agujero cubierto con una lienza de cosa de dos pulgadas de largo y poco más de media de ancho, la cual levantada se hallaron dentro algunos algodones, y después de ellos unas cuantas tiras de papel común, prendidas a la horma con un alfiler todo enmohecido y verde, sin afectar a aquélla en lo más leve, pues esa cavidad no tenía más profundidad que el espesor de las cañas que componen la parte muscular de dicho punto. Los algodones están manchados y adheridos por una materia glutinosa de color verdoso y amarillento, y los papeles de un rojo oscuro, deslavado en partes, también amarillento; exhalando todo el mismo olor que se percibe en el pie derecho, según se ha escrito en el acta, pero con mucha mayor fuerza y viveza, la cual no ha disminuido, a pesar cle haber transcurrido un mes desde que se quitaron esos algodones del hueco dicho, hasta la fecha en que esto se escribe, y que diariamente se han expuesto varias veces al aire libre por satisfacer la curiosidad de algunas personas." 17

La secuencia de los dos exámenes, con su intervalo de más de siglo y medio, permitirá al curioso lector advertir los cambios introducidos en la composición de la imagen, al repararse una y otra vez. Es posible percibir que al pegamento original -tatsingueni, en lengua tarasca-sucede la cola introducida por los españoles pero advirtiendo la centenaria consistencia del producto nativo. En fin, gracias al minucioso relato que hoy exhumamos, se pone muy en claro el procedimiento seguido en el siglo xvi para formar las imágenes de caña de maíz. No en vano el hombre del altiplano prehispánico se adelantó a Pascal cantando "la cañaeja verde del hombre".

17 Ibid., pp. 171-76. 